Med Princ Pract 2014;23:486

DOI: $10.1159 / 000362795$

\section{Should Renal Function Become an Important Factor in Cognitive Impairment and Cognitive Decline?}

\section{Min Li, Zhenyu Tang}

Department of Neurology, The Second Affiliated Hospital, Nanchang University, Nanchang, China

\section{Dear Editor,}

During the past decades, a strong body of evidence has demonstrated that the incidence of dementia is high in patients with diabetes or high glucose levels $[1,2]$. Since the late 1980s, vascular risk factors have been the major focus of numerous etiological studies for dementia [3]. The associations of several vascular risk factors (such as smoking, obesity, and alcohol consumption) with dementia have been supported in systematic reviews and quantified in meta-analyses of prospective studies [4]. However, not all studies have shown that diabetes affects the risk for dementia [5], although previous meta-analyses have yielded consistent results that diabetes is a risk factor for developing dementia [including Alzheimer's disease $(\mathrm{AD})$, vascular dementia $(\mathrm{VaD})$, and any dementia] $[1,6,7]$.

Recently, Crane et al. [2] reported that higher glucose levels may be a risk factor for dementia, even among persons without diabetes. This finding is consistent with the Hisayama study of Ohara et al. [8]. They suggested that diabetes is a significant risk factor for all-cause dementia, $\mathrm{AD}$, and probably VaD. Meanwhile, 2-hour postload glucose levels, but not fasting plasma glucose levels, are closely associated with an increased risk of all-cause dementia, $\mathrm{AD}$, and $\mathrm{VaD}$. However, a prospective study by Thambisetty et al. [9] found that measures of glucose and insulin homeostasis are not associated with $\mathrm{AD}$ pathology and likely play a small role in $\mathrm{AD}$ pathogenesis.

In view of these inconsistent findings, it is imperative to explore the variable methodological quality of longitudinal studies. After reviewing the previous observational studies [10,11], all are limited by the fact that the established and readily available confounder of renal function was not accounted for. In the USA, there are an estimated 7.5 million individuals with moderate renal disease [12]. It has been shown to be associated with an excess risk of incident dementia among persons in good-to-excellent health. As reported by Fukunishi et al. [13], there is a $2.5 \%$ annual incidence rate of dementia among elderly individuals on dialysis, which is more than double the rate reported in the Japanese general population. Thus, the change in renal function is related to the change observed in global cognitive ability. In addition, elevated albuminuria levels are also associated with a faster decline in cognitive function.

In conclusion, this evidence leads us to state that it is necessary to recognize renal function as an important factor in cognitive impairment and cognitive decline.

\section{References}

1 Kopf D, Frolich L: Risk of incident Alzheimer's disease in diabetic patients: a systematic review of prospective trials. J Alzheimers Dis 2009; 16:677-685.

2 Crane PK, Walker R, Hubbard RA, et al: Glucose levels and risk of dementia. N Engl J Med 2013;369:540-548.

-3 Kloppenborg RP, van den Berg E, Kappelle LJ, et al: Diabetes and other vascular risk factors for dementia: which factor matters most? A systematic review. Eur J Pharmacol 2008;585:97-108.

4 Qiu C: Preventing Alzheimer's disease by targeting vascular risk factors: hope and gap. J Alzheimers Dis 2012;32:721-731.

5 MacKnight C, Rockwood K, Awalt E, et al: Diabetes mellitus and the risk of dementia, Alzheimer's disease and vascular cognitive impairment in the Canadian Study of Health and Aging. Dement Geriatr Cogn Disord 2002;14:77-83.

6 6 Profenno LA, Porsteinsson AP, Faraone SV: Meta-analysis of Alzheimer's disease risk with obesity, diabetes, and related disorders. Biol Psychiatry 2010;67:505-512.

7 Cukierman T, Gerstein HC, Williamson JD: Cognitive decline and dementia in diabetes - systematic overview of prospective observational studies. Diabetologia 2005;48:2460-2469.

8 Ohara T, Doi Y, Ninomiya T, et al: Glucose tolerance status and risk of dementia in the community: the Hisayama study. Neurology 2011;77: $1126-1134$.

-9 Thambisetty M, Jeffrey ME, Yang A, et al: Glucose intolerance, insulin resistance, and pathological features of Alzheimer disease in the Baltimore Longitudinal Study of Aging. JAMA Neurol 2013;70:1167-1172.

10 Allen KV, Frier BM, Strachan MW: The relationship between type 2 diabetes and cognitive dysfunction: longitudinal studies and their methodological limitations. Eur J Pharmacol 2004;490:169-175.

11 Biessels GJ, Staekenborg S, Brunner E, et al: Risk of dementia in diabetes mellitus: a systematic review. Lancet Neurol 2006;5:64-74.

$\checkmark 12$ National Kidney Foundation: K/DOQI clinical practice guidelines for chronic kidney disease: evaluation, classification, and stratification. Am J Kidney Dis 2002;39(suppl 1):S17-S31.

13 Fukunishi I, Kitaoka T, Shirai T, et al: Psychiatric disorders among patients undergoing hemodialysis therapy. Nephron 2002;91:344-347.

\section{KARGER}

E-Mail karger@karger.com www.karger.com/mpp
(C) 2014 S. Karger AG, Basel

This is an Open Access article licensed under the terms of the Creative Commons Attribution-NonCommercial 3.0 Unported license (CC BY-NC) (www.karger.com/OA-license), applicable to the online version of the article only. Distribution permitted for non-commercial purposes only. 